\title{
Design and implementation based on ERP in the clothing sales management system
}

\author{
Fengqin Chen ${ }^{1, a}$ \\ ${ }^{1}$ Jiangxi Institute of Fashion Technology, Jiangxi, Nanchang, 330201 \\ a18235291@qq.com
}

Keywords: Clothing; Sales management system; Prototyping; ERP

\begin{abstract}
Clothing industry has long been the important sector of the economy in our country, our country has become the largest garment producer and exporter, but from the clothing powers and the larger gap. Under the background of economic globalization, the apparel industry must strengthen the use of computer technology and information technology, namely the transformation of the ERP implementation garment industry. This article will first analyze the current development trend of clothing sales management system, discuss the concept of ERP and CRM management integration. And from the system development model, system general objective, such as demand for sales management system analysis and design, finally discuss the development and implementation of sales management system.
\end{abstract}

\section{Introduction}

In the rapid development of computer technology today, clothing enterprises also usher in a new development opportunity, should speed up from labor-intensive industries to the transformation of science and technology intensive industries. In order to improve the current marketing of clothing sales, production, procurement, payment and so on a series of links, must accelerate the improvement of the electronic sales platform, so as to make the information flow and value flow of enterprise integration, to achieve a higher economic efficiency.

\section{Clothing sales management system development trend}

The so-called ERP refers to the clothing enterprise is regarded as a supply chain, connect factories, distribution network and customer. And internal implementation in the enterprise finance, quality management, marketing, etc, also including financing, investment management, etc. Sales management system belongs to the subsystem of ERP, the system of quality decision enterprise lifeblood, and closely contact with other subsystems. Sales management system to the production planning management and then send the request information, send customer feedback to quality management, financial information will be sent to the financial management, to provide the delivery information for warehouse management, and at the same time the personnel information can be provided to the personnel management, in a nutshell, sales management system is the core of enterprise operation.

In information technology highly developed today, more and more IT tools used in sales management, including the Internet the most widely used, past the low efficiency of sales management step by step, is to take the customer as the center of the sales management. The clothing sales management system development mainly shows the main trend in two aspects: on the one hand, as the electronic commerce, so business related researchers even far apart on the space, also can make the business process in time; On the other hand for CRM customer relationship management (CRM). At present to customers, suppliers and partners together can greatly promote the competitiveness of the enterprise.

\section{The integration of ERP and CRM management theory}

Previous ERP will focus on resources integration and business management, also sales management, quality management, etc. CRM is more valued customer resources the development and operations, meet the personalized needs of customers as much as possible. Have a intersection 
between ERP and CRM, and interdependent relationship. ERP can provide a wider fuller data for CRM, and the advantages of CRM on the forecast of market development can help the ERP decision, from a certain perspective CRM is an extension of the ERP system. Clothing enterprise if only using the CRM system, unable to grasp the background information, in the business layer and data flow between the fault serious; If the adoption of ERP system, sales and service support network appear more. Therefore clothing sales management system should be integrated ERP and CRM system, can increase a few cost under the condition of multiple amplification of functionality.

\section{Sales management system analysis and design}

According to the analysis above sales management system is the core of the clothing enterprises, but also become the main part of ERP. Sales as operations at the last step, to realize the enterprise value chain is. Garment enterprises in China are mostly labor-intensive, economic scale effect is insufficient, therefore, clothing enterprise sales management system based on ERP construction is imperative.

System development model. At present, a lot of management information system using life zhou qi, prototype method and object-oriented development methods. One life curse volley before development need to define requirements, however, incomplete requirements, project developers deficiencies, problems such as too complicated, so the author USES the prototyping development. Prototype method is based on the analysis to understand users' needs and, after establishing the system prototype before analysts and the user's communication, and evaluate the model and modified. Prototyping developers, and users can more easily communication, in a powerful database system, visual programming tools support, more and more get the favour of the developer.

In the clothing sales management system based on ERP development using prototype method, first of all, with the help of ASP.NET development prototype, the prototype will focus on the screen display module, can save data update time, also has realized the function of simplified. Because the prototype is mainly used for demo, can omit part of the module function. Developer divide the process of communication with customers, the prototype image can make customers more understanding of the hair development solutions, evaluation is in accordance with the requirements. In addition, the prototype as a foundation for the later work, also more convenient to determine the working process. But because of the development of the prototype and didn't get the user demand accurately, so there will be more defects, which requires for prototype implementation changes many times.

The system total goal. Clothing sales management system overall goal is to further improve the existing market chain process, the various subsystems tightly integrated, timely collect user needs to adjust the sales plan, optimize the delivery, collection and after-sales process, set up the enterprise internal and external information bridge, strengthen the internal and external information exchange, make online quotation system such as possible. Within the enterprise to realize the order management, billing and settlement of track management, improve the efficiency of the existing contract execution, make the enterprise market competitiveness.

Specifications for system development. Sales of clothing enterprises sign a contract work usually take the customer as a starting point, and then respectively by planning department to arrange production, delivery order issued. Considering the integrated sales business processes, the system requirements can be divided into two aspects of internal information and external sales information. Internal sales information management, need from sales business process analysis, cutting management activities for different activists have bigger difference. For sales management should be provided to the processing and trading, sales analysis report for the sales manager should reach the orders and sales of global management, administrators should implement inventory management for warehouse inventory, for financial personnel should have sales invoice management. Order management should satisfy the order query, perform, modify and delete functions; Contract management should be implemented to add, modify, and query functions; For invoice management implementation query functions; Electronic product management should meet the product description and the function of the order. External sales information management, can 
be realized through the form of HTML pages information release, can promote the enterprise image and reputation, also have a more comprehensive understanding of the enterprise makes the outside world. Activists of the system include the new users and companies, thus determine the activities of the purpose for the product quotation, online order acceptance and information query, customer service and support.

System analysis. The so-called system analysis is to determine the model according to the development demand. Basic data collection including product data management, product cost management and contract management. Marketing planning is an important factor of decision enterprise sales, so should from the perspective of customer information sales plan feasibility analysis, to guide the production process. Enterprises through the salesman master user requirements and Suggestions, after the overall sales plan to complete the report of production, on the one hand, since this can show the actual sales, on the other hand can analyze the input-output ratio, in-depth analysis of enterprise profit and loss situation. The customer can arrange the customer information management, through the files stored customer information, including name, region, type, etc. The main information. Contract management should record the customer information, and according to the receiving unit, the review of customer information.

\section{Clothing sales management system development and implementation.}

The realization of the function of different modules. Extranet function. The realization of the function of extranet enables users to query information about enterprise directly, through the network according to own needs to realize the directional operation, this operation immediately feedback to the enterprise, so the early movers in commercial activities. Extranet page this system is mainly composed of products, company profile, organization, contact us, such as modules, you can use Macromedia Flash MX module design. Product module is direct display of products, will be important first impression to the customer. In addition, the company mainly to help customers to better understand enterprise operation and enterprise culture; Different parts of the organization module to show enterprise and those responsible. This system enterprise organization can be divided into the production manager, design director, marketing manager, financial manager and hr manager. Contact the company address and phone number given in the module, you can also set a message board, increase the interactive system.

Development and implementation of Intranet function. Intranet users for internal employees, including product display, order management, sales plan and the customer information the four modules. When trying to into the network through the network, will be required to provide the user permissions, the permissions interface using the Form authentication way, thus effectively improve the system security. Order management module is the most complex function module, its main function as order management, but at the same time also have product management, order processing, inward and outward query, and other functions. Order management module can be used as the network user management module, once the order generated, relevant staff can order management function process orders in a timely manner. Order management, the administrator login window is designed, and could be divided into super administrator privileges manager and general manager. The former mainly for the sales manager and the latter as the ordinary employees, it results from the system security Settings. Product display module can realize the product list of specific classification and function, and show the detailed information such as fabrics, style, selling point, also discuss with professional language sewing process, and can use the FLASH. Outbound query module can provide product inventory queries, so as to confirm the order.

Sales plan module and the tube can be subdivided into contract, invoice management, and the salesman query three modules, with the help of contract management module can help enterprises to combine the CRM and ERP, on the one hand, sets up the enterprise image and the prestige, on the other hand to the lawful rights and interests maintenance enterprise to the greatest extent. Contract management module of security requirement is higher, also should be set user permissions (divided into two categories, administrators and users), administrator permissions can modify the contract, and access to the user as a read-only state. The customer information system is characteristic of 
ERP and CRM combining application modules, and by the suppliers, purchase with file upload three sub modules.

The development of the module function. The new user registration page as an important part of customer service system, code the demand is higher, at the same time use to data-bound controls and ASP. Product management need to provide more detailed product information page, so you need to have the search function, the page development using ASP.NET interactive technology, and with the aid of the Session in the $C$ language to achieve. Contract management page using the Session and Application.

As clothing enterprise sales management system database, should possess integrity, consistency and recoverability, safety principles, in the actual design process in order to avoid a long response time, may be redundant, but increase the redundancy and consistency problems, visible to realize these principles should be weighed. The current network with CGI and JDBC database and ASP these three technologies, relatively open standard of CGI, the principle of easy to understand, however poor interactivity, processing efficiency is low; JDBC application often perform the inefficient problem, this is mainly because the network width limit the download speed. ASP not only takes up a small amount of disk space, and can write applications to access and operation, more flexibility.

\section{Conclusion}

Clothing sales management system based on ERP is an important means of the current clothing enterprises development, the design and implementation of the management system are analyzed above, has certain guiding significance in practice. But the clothing enterprise sales management system security problem is still serious, potential security issues including system penetration, in violation of the principle of authorization, communication monitoring and harass, interrupt service, deny and forgery, etc., this is also the future clothing sales management system development must solve the problem.

\section{Reference}

[1] Qian lin. Based on.net clothing sales management system design and implementation [D]. Xiamen university, 2012.

[2] Zhaoxin $\mathrm{Xu}$. Based on the B2C online drug sales management system [J]. The design and implementation of project study, the interdisciplinary field of engineering, 2014, (4).

[3] xiaoqian Ma. The design and implementation of online clothing sales management system [J]. Journal of packaging world, 2015, (4). 